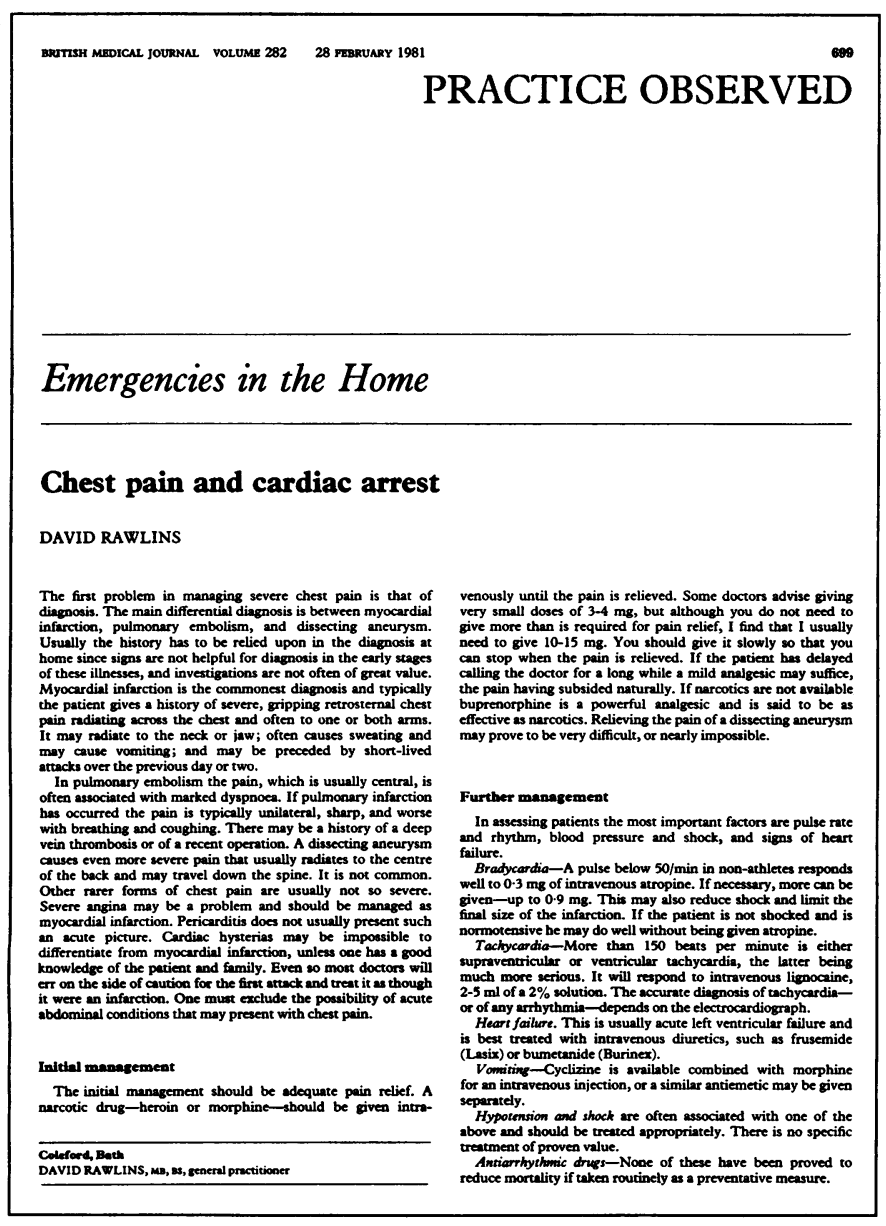

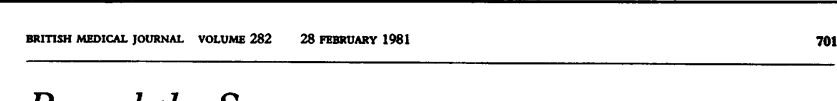

\title{
Beyond the Surgery
}

\section{General practitioner at school}

H G BARNES

Since $1969 \mathrm{I}$ have been school medical officer to the Newcostle
Royal Grammar School. I succededed Dr Andrew Smith in a job

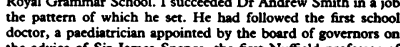

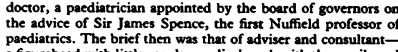

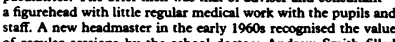

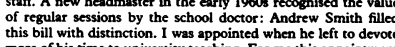

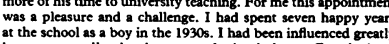

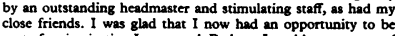

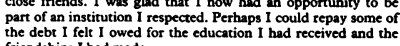

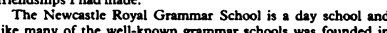
like many of the well-known grammar schools was founded in
bifuf

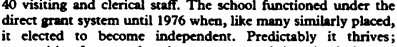

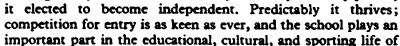
Newcastle.
Is started with a fecling of anxiety and strangeness in my new

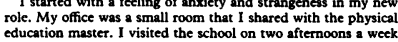

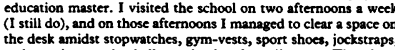
embrocation, rugby balls, and other impedimenta. The chaos
and sweary arome of this office did nothing for my medical image

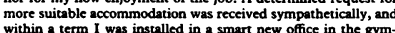

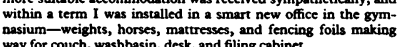

Looking affer 1000 boys

But what of the job itself? Why have a doctor for $a$ school of
1000 apparently healchy boys ? $1 \mathrm{am}$ sure that a portion of what I

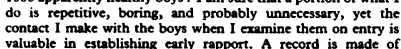

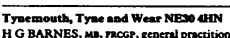
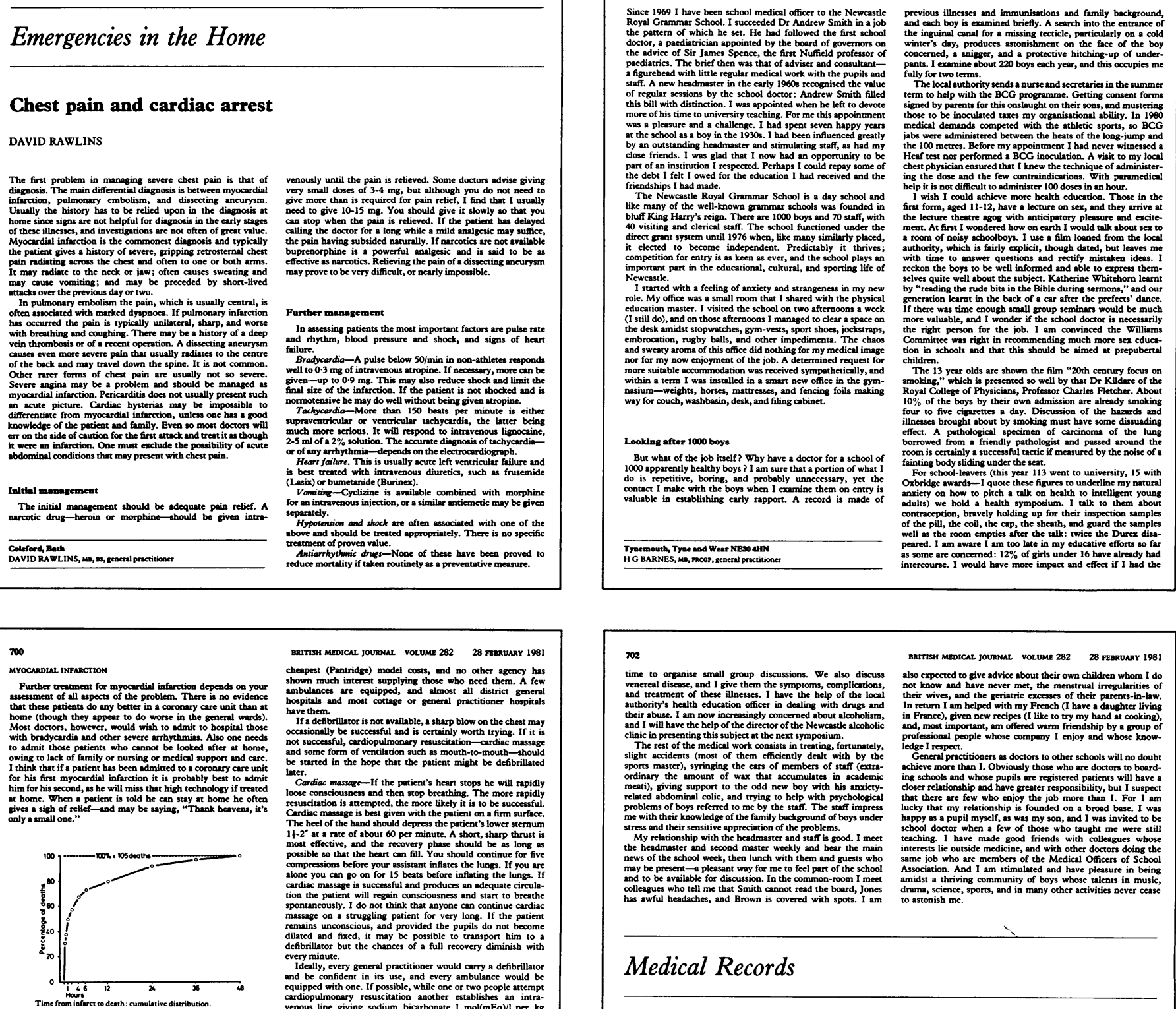

Investigations in the carly stages are not likely to be of much
use beceuse six hours sffer the onset of pain $Q$ waves have only

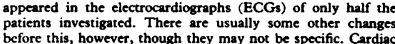

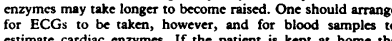

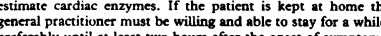
preferably untili at last twe hours sfter the onset of symptoms
He should be willing to revisiti the same day if necessary and on daily basis for the nert few days. It is best to get the patient
moving affer not more than two or three days in teded Patient always be admitred to hospial.
Cardiec arrest-The most hazardous time is the first feuw minteses atere the onset of symptoms. Afer this the chancess

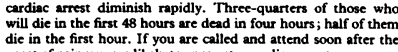
dic in the first hour. If you are called and attend soon affer the
onsect of pain you are likely to oencounter cardiac arrest.

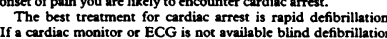

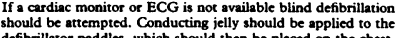

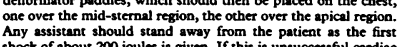

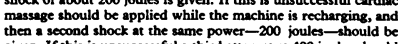

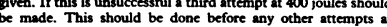

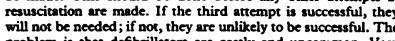

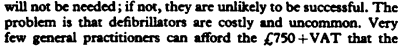

BRITISH MEDICAL JOURNAL VOLUME $282 \quad 28$ FraRuARY 198 cheapest (Pantridgec) model cosst, and no other agency has
shown much incerest supplying those who need them. A few shown much interest supplying those who need them. A few
ambulances are equipped, and almost all district general
hospitals and most cotrage of generel prectitioner hospitals have them.
If a defibrillator is not available, a sharp blow on the chest may occasionally be successful and is cerrainly worth trying. If it is not successful, cardiopulmonary resuscitation-cardiac massage
and some form of ventilation such as mouth-to-mouth - should and some form of ventilation such as mouth-to-mouth-should
be started in the hope that the patient might be defibrillared Cardiac massage-If the patient's hearr stops he will rapidly resuscitation is antempred, the more likely it is to be succossffu. Cardiac massage is best given with the patient on a firm surface. 11-2"- at a rate of about 60 per minute. A short, sharp thrust is
most effective, and the recovery phase should be as long as
possible so that the heart can fill. You should continue for five compressions before your assistant inflates the lungs. If you are
alone you can
go on cardiac massage is sulccessful and produces an ad equarte circellat
tion the patient will regain consciousness and start to breathe spontaneously. I do not think that anyone can continue cardiac massage on a struggling paticent for very long. If the patient
remains unconscious, and provided the pupils do not become remains unconscious, and provided the pupils do not become
dilated and fired, it may be possisle to transport him to
defibrillator but the chances of a full recovery diminish with every minute.
Ideally, every general practitioner would carry a defibrillato and be confident in its 1 use, , and every a ambulannce would be
equipped with one. If possible, while one or two people ureem equipped with one. If possible, while one or two pecoplc artempt
cardiopulmonary resuscitation another establishes an intracardiopulmonary resusciation another establishes an intra-
venous line giving sodium bicarbonate 1 molmEg (m) per
body be given every 10 minutes. If resuscitation from ventricular
fibrillation is successful, the patient should be started on

The "caft coronary"

This cause of sudden death, although it does not usually
occur in the home, should be briffly mentioned. A bolus of

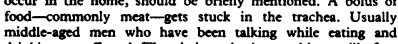
middle-aged men who have been talling while cating an
drinking are affected. The victim, who in speechless, will often drinking are affected. The victim, who is speechless, will offte
grab at his throat and be terrified. The quickest and best treatment is to get behind the viccim, encircle his chest or upper
abdomen with your asms, and give a sudden sharp squecere, Heimlich manoeuvre).

I should like to thank Dr R D Thomas, consultant cardiologist at
the Royal United Hospital, Bath, for his advice.

THovch I have endeavoured to render this Treatife plain and uffeful,
yet I found it impoofible to avoid fome terms of art; but thofe are, in general, either explained, or are fuch as molt people undertlas

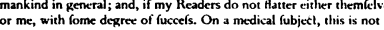
ceafy a matter as fome may imagine. To make a fhew of cerrning
eafier than to write plain fenffe, efpecially in a fcience which has beren kept at fuch a dittance from common oblervation. It would, however

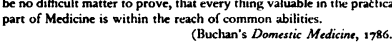

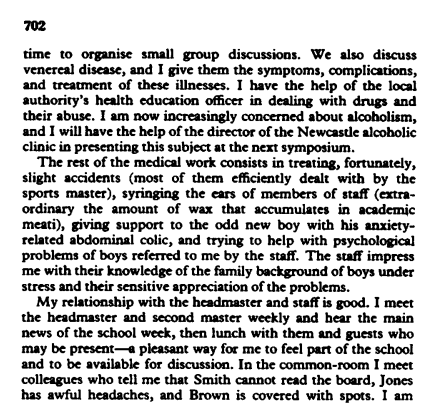

BRITISH MBDiCAL JOURNAL VOLUME $282 \quad 28$ FranUARY 1981 also expected to give advice about their own children whom I do
not know and have never met, the menstrual irregularities of their wives, and the geriacric excesses of their parentrs-in-lave in France), given new recipes (I like to try my hand at cooking),
and, most important, am offered warm friendship by a group o

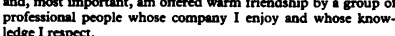
ing schools and whose pupils are registered patients will have
athere closer relationship and have gereater responsisibitity, but I suspect
that there are few who enjoy the iob more than I. For I am chool doctor when a few of those who taught me were still teaching. I have made good friends with colleagues whose
interess li curstide medicine, and with other docorrs doing he
same iob who are members of the Medical Officers of School Associa na. And $1 \mathrm{am}$ stimulated and have pleasure in being drama, science, sports, and in many other activities never cease

\section{Medical Records}

\section{History of our records}

IAN TAIT

I think that medicine, for a learned profession, is sadly neglectful
of its own history. A historical perspective often helps us to see why it is that things are as they are and indicietes the direction in
which it is right for us to move. The history of our records in general practice has much to teach us.
It sometimes seems that our present record system is assumed It sometimes seems that our present record system is assumed
to be an inevitable fact of fife and therefore unallererale. The truth is, of course, that it is the consequence of decisions,
compromises, and chance events. It is not inevitable. It is bound
to change, and we have to try to see how we got where we are to change, and we have to try to see how we got where we are
and what we now have to do to achieve the kind of records we need. This article summarises the main events and influences
that have created our present record. It also secks to identify the need. This arcicle summarises the main events and infuences
that have created our presentr record. II also oceks to identifit the
main reasons for our apparent inability to introduce chenges in main reasons for our apparent inability to introduce changes in
our record-keeping system when these were seen to be required
and will try to indicate what lessons the history of our records
has to guide our efforts in the furure.

Beginnings

We can trace the origins of our record system to Lloyd
George's National Insurance Act of 1911 . Under that Act the

Nebburgh, Suffolk
IAN TAIT, ma, macor, male working population between the ages of 16 and 70 werc provide medical services for insured patients. The Government Act. For this reason the Act included a clause that imposed upon general practitioners who participated in the scheme an obli-
gation "to keep such medical records as might be required of
them und TIN BoxEs

In 1913 a form of record was introduced for this statistical
purpose. At the end of the year the doctor was ree purpose. At the end of the year the doctor was required to return
his record for analysis. For our purposes, the only interesting to keep them. These records were in use until 1917 , when they were given up as a temporary wartime measure. After the first
world war the question of what kind of record should be kept $b$. "To consider and advise the Minister of Health and the
Scortish Board of Health as to the form of medical record to be Scortish Board of Health as to the form of medical record to be
prescribed under the conditions of service for medical practigeneral practitioners had to be reconsidered. An advisory com-
mitree (the Rollesson Commitree) was set up in 1920 with the
following terms of reference: General practitioners as doctors to other schools will no doubt he health of the working population that might be made avai-
ble as a result of the medical care given under the terms of the 